\title{
CHI 2020: Right Here, Right Now?
}

\author{
A bottom-up approach to estimating the carbon emissions from more \\ than twenty years of $\mathrm{CHI}$ conference travel.
}

Jason T. Jacques

University of Cambridge

Cambridge, UK

jtj21@cam.ac.uk

\section{Abstract}

Over the last twenty years the $\mathrm{CHI}$ conference has grown substantially. However, with the reframing of climate change as a climate crisis, environmental concerns have become increasingly pervasive in the community. In $2019 \mathrm{CHI}$ introduced a sustainability role and set a goal to make $\mathrm{CHI}$ more sustainable. In $2020 \mathrm{CHI}$ is in Hawaii. This work looks back over the last two decades and estimates what are substantial and growing $\mathrm{CO}_{2}$ emissions from conference travel. First, it posits how, in the short term, potential environmental damage can be minimised. Second, and longer-term, it invites the community to reflect on research dissemination and how the conference experience may need to change.

\section{Author Keywords}

Conference attendance; $\mathrm{CO}_{2}$ emissions; sustainability

Permission to make digital or hard copies of all or part of this work for personal or classroom use is granted without fee provided that copies are not made or distributed for profit or commercial advantage and that copies bear this notice and the full citation on the first page. Copyrights for components of this work owned by others than the author(s) must be honored. Abstracting with credit is permitted. To copy otherwise, or republish, to post on servers or to redistribute to lists, requires prior specific permission and/or a fee. Request permissions from permissions@acm.org. CHI '20 Extended Abstracts, April 25-30, 2020, Honolulu, HI, USA.

Copyright is held by the owner/author(s). Publication rights licensed to ACM ACM ISBN 978-1-4503-6819-3/20/04 ...\$15.00

\author{
CCS Concepts \\ -Applied computing $\rightarrow$ Environmental sciences;
}

\section{Introduction}

The closing years of the last decade have been a hallmark period for environmental awareness. From increasing public concern about plastic pollution, the spotlight shone on the IPCC SR15 [9] by the skyrocketing profile of Greta Thunberg, and the reframing of climate change as a climate crisis and climate emergency (even by western governments) has raised conservationist concerns to new heights.

Social concerns have long been a feature of $\mathrm{CHI}$, with themes including "changing the world" (2002) and "\#chi4good" (2016). Environmental considerations are no exception. In 2008 a session dedicated to these concerns was featured. Entitled Green Day ${ }^{1}$, the session showcased three papers focusing on environmental considerations around technology: creation, use, and disposal. Sessions in this vein continue to feature throughout the proceedings.

In 2019, CHI set an explicit goal to become more sustainable [6]. In a blog post, on the conference website, the authors of the entry highlight the carbon intensity of air travel and consider this in the context of moving to a virtual program committee. The authors set goals to locally source

\footnotetext{
${ }^{1}$ https://dl.acm.org/doi/10.1145/3256546
} 
food, to reduce food miles, reduce waste, and encourage shared transportation. Importantly, to quantify and measure the impact of future actions, the authors commit to "benchmark the overall carbon footprint" of the event and report on these findings in future posts.

In the absence of any reported findings this work attempts to provide one piece of that puzzle.

\section{Background}

Held periodically from 1982 and annually since 1985, CH is the premier conference in the field of human-computer interaction and is the flagship of the Association for Computing Machinery's Special Interest Group on Computer Human Interaction (ACM SIGCHI) [16]. From fewer than 1,000 attendees, and compact programs, $\mathrm{CHI}$ has grown to its current multi-track format with 703 papers and an estimated 3,800 attendees at the 2019 event.

$\mathrm{CHI}$ offers an environment where research is disseminated, connections made, ideas shared, and attendees mingle. In light of the recent focus brought on sustainability [6] and a renewed global interest in limiting global temperature rise, this work offers a data-driven perspective on the potential environmental impact on one aspect of attendance: travel.

\section{Conference Attendance}

Since at least $2002 \mathrm{CHI}$ has, with increasing vigour, called on authors of accepted papers to present their work at the conference: 2002-2008, "authors of accepted papers will present”; 2009-2012, "authors must present”; 2013-2017, "authors are required to present". Further, since $2018 \mathrm{CH}$ has required authors to accept a "Submitter Agreement" explicitly including an attendance provision.

Authors and attendees will travel to and from the conferences via a variety of means. However, personal vehicles and air transport together represent the overwhelming majority of all journeys, with a combined share in excess of $95 \%$ [19]. Air travel is one of the most significant causes of global $\mathrm{CO}_{2}$ emissions from long-distance transportation, second only to global shipping [4]. As journey length increases air transport becomes increasingly prevalent. For journeys of 750 miles $(1,200 \mathrm{~km})$ or more air travel represents the majority choice [19].

\section{Methodology}

To determine the environmental impact of conference travel this work considers two parts of the attendance profile: a) paper authors and b) an approximation of the estimated total attendance, based on prior surveys and a model of attendee make up.

Main Proceedings Authors

Using an approach similar to that of Bartneck and $\mathrm{Hu}$ [1] and Sakamoto [15], the list of authors was compiled from the available proceedings on the ACM Digital Library (ACM DL) for each year of the conference between 2000 and 2019. The DOI for each of the 6,223 papers ${ }^{2}$ was extracted, and the article citation page was collected. The ACM DL has both policy-based access restrictions ${ }^{3}$ and technical measures which preclude automatic data collection. As such, manual acquisition techniques were required. Data was collected, in order of preference, from a) the Internet Archive $^{4}$, b) the Microsoft Bing cache ${ }^{5}$, and, only where necessary, c) directly from the ACM $\mathrm{DL}^{6}$.

For the purposes of this work, it is assumed that the authors of the relevant publications travelled both to and from

\footnotetext{
2 See Table 1

3 https://libraries.acm.org/digital-library/policies

4 https://archive.org/web/

5 https://help.bing.microsoft.com/\#apex/18/en-us/10016/0

${ }^{6} \mathrm{https}: / / \mathrm{dl} . \mathrm{acm}$. org
} 
the conference from their then affiliated institutions. This provides an approximation of each author's probable start and end location. For a more nuanced discussion of this assumption, please refer to Limitations. Each collected article citation page was processed to extract the list of authors and their institutional affiliation, for a total of 24,569 records. For each institution the city or administrative unit, region (e.g. state), and country was manually tagged. In the limited number of cases where authors listed multiple institutions, the most completely addressed was adopted, or where ambiguous the first listed was used.

To ascertain the distance between the conference and the author, the latitude and longitude of each tagged location was identified using the OpenStreetMap Nominatim service $^{7}$. Aircraft are typically assumed to follow the shortest distance between points, known as the orthodromic or great-circle distance. The distance between the location of each institution and the conference, in kilometres, was calculated using the Great Circle Calculator ${ }^{8}$ with the WGS 84 geodetic model, the reference coordinate system for GPS.

\section{Estimating Total Attendance}

SIGCHI publishes the attendance figures for each $\mathrm{CHI}$ conference. For the years 2004-2015 the summary responses to the post-conference survey were also made available. In addition, starting in 2008, this data includes the work location of respondents, offering insights into the travel country of origin for the broader group of $\mathrm{CHI}$ attendees.

There are many factors that may influence an individual's decision to attend a conference. One of the most cited, as identified by the $\mathrm{CHI}$ surveys, is having an accepted work [16]. The published survey data indicates that more

\footnotetext{
7 https://nominatim.openstreetmap.org

8 https://edwilliams.org/gccalc.htm
}

than $50 \%$ of all attendees are authors, and survey responses indicated that this proportion was growing. A second important factor is the distance to the conference location. While, on its own, distance may not directly impact an attendance decision, it potentially offers a way to flatten a number of complex factors into a uniform metric. Such factors may include available travel modes (e.g. road, air), likelihood of requiring travel documentation (e.g. none, passport, waiver, visa), cost of transit, and the required duration of the trip.

Based on published survey data, a model of attendance was generated using regression analysis on a per country basis. Using a country-based model provides a more nuanced estimate of attendance, accounting for factors including affordability concerns and travel considerations such as freedom of movement or conversely exit and entry restrictions. To estimate the likely makeup for attendee origin, the author composition for the given year is used. To localise survey attendees travelling from countries where no authors are reported to be based, the capital city is used. Further, as discussed above, the distance between the attendee and the conference location is incorporated.

This model provides estimated attendance makeup for each of the countries from which authors and attendees were identified as travelling over the 20 year period. Combined with the reported attendance figures this provides an estimate for attendance from each country in the dataset. To provide forecasts for future conferences where the attendance and authorship data is unavailable (2020 and 2021 at the time of writing), the typical authorship for the analysed period and projected total attendance figures were used.

Estimating $\mathrm{CO}_{2}$ Emissions

While attendees may travel to conference destinations by a number of different modes, personal vehicle and air travel represent over $95 \%$ of all journeys, irrespective of 
distance [19]. Air is the predominant mode of travel for distances in excess of $1,200 \mathrm{~km}$.

Aircraft $\mathrm{CO}_{2}$ emissions are dependent on a large number of variables including, type, load, distance, speed, and altitude. Per passenger calculations must also consider factors including the number of seats, load factor, luggage, and class of travel. Notably, for otherwise constant values it is important to note that per kilometre emissions typically reduce as distance increases. This inverse relationship is partly the result of amortisation of fixed emissions such as those from taxiing, take-off, stacking, and landing.

To provide representative real-world estimates, this work uses the ICCT emissions figures which are derived from a bottom-up model of the global emissions characteristics of the 38 million passenger-carrying flights taken in 2018 [7]. The consolidated figures are stratified by stage length in $500 \mathrm{~km}$ increments and indicate the typical value for grams of $\mathrm{CO}_{2}$ per passenger $\mathrm{km}$ for each stage length.

For regional and local attendees, alternative transport is increasingly likely to be used. For journeys between 50 and 499 miles $(80-800 \mathrm{~km})$, personal vehicles represent over $95 \%$ of all trips [19]. Based on EPA figures, the average passenger vehicle emits $404 \mathrm{~g} \mathrm{CO}_{2}$ per mile [18] (251 g $\mathrm{CO}_{2}$ per $\mathrm{km}$ ). Considering typical vehicle occupancy of $1.67(2009,2017)$ [12], this suggests an estimated value of $150 \mathrm{~g} \mathrm{CO}_{2}$ per passenger $\mathrm{km}$. For journeys in excess of $500 \mathrm{~km}$ aircraft emit $109 \mathrm{~g} \mathrm{CO}_{2}$ or less per passenger $\mathrm{km}$ [7]. The relatively high level of emissions from passenger vehicles means that the these journeys are only competitive with aircraft for distances shorter than $500 \mathrm{~km}$ and when transporting at least two individuals.

In accounting for the two predominant transport modes, the presented $\mathrm{CO}_{2}$ estimates assume the most efficient option was selected: air transport for journeys in excess of $500 \mathrm{~km}$, and passenger vehicle for journeys between 80 and $500 \mathrm{~km}$. Finally, to avoid overstating emissions for hyperlocal attendees, the presented estimates zero-rate emissions for journeys of less than $80 \mathrm{~km}$.

To allow further analysis, the complete dataset and calculations can be found in the accompanying data file available from: https://doi.org/10.17863/CAM.48681

\section{Data Analysis}

Conference impact can be measured in a number of ways. It is important to remember that $\mathrm{CHI}$ has a purpose: the dissemination of research, the connecting of people, the sharing of ideas. And here $\mathrm{CHI}$ has been an unmitigated success, demonstrating decades of year-on-year growth.

Papers, as a unit of research, may offer an interesting lens on the overall impact of the conference and allow us to weigh the social good of our work against any ecological concerns. More objectively, however, per-attendee emissions estimates offer a scaled metric for the potential environmental implications of individual conference travel. It is also important to remember that the overall estimates do not exist only as analytical tools or statistical curiosities; but rather an aggregate total with potential real world impact. An impact that can be measured in metric tons of $\mathrm{CO}_{2}$.

Growth

Since the turn of the millennium, the growth of the $\mathrm{CHI}$ conference has been remarkable. As seen in Table 1, from lows of just 61 papers (and a 15\% acceptance rate) in 2002, and 1,435 attendees in 2003, CHI 2019 was the biggest year to date with 703 papers in the main proceedings alone and an estimated attendance of 3,800 [16]. This represents more than $1,000 \%$ growth in accepted submissions and well in excess of a doubling of attendance over 
the intervening 16-17 year period. Anecdotally, this growth is regularly seen highlighted in the closing plenary: growth is considered a measure of success.

As $\mathrm{CHI}$ has grown, both in size and influence, the imperative to publish at the conference has become insatiable. With the notable exception of the 2002 and 2003 conferences, the acceptance rate has held steady around $25 \%$ yet the number of papers published has ballooned. While the number of authors has similarly scaled, the number of papers per author has shown a creeping trajectory from just over one per author to as high as 1.25 in more recent years.

Table 1: Papers, unique authors, and attendance in the compiled dataset, with mean values for authors per paper and papers per author, along with overall attendees per paper.

Paper numbers reflect the number of papers and notes listed on the ACM DL proceedings page and may differ from officially reported figures. Italicized text indicates forecasts or estimates.

\begin{tabular}{llrrrrrr}
\hline Year & Location & Papers & $\underline{\text { Authors }}$ & $\underline{\text { Attendees }}$ & Au on P & P by Au & At / P \\
\hline 2000 & The Hague, NL & 72 & 221 & 2628 & 3.29 & 1.07 & 36.50 \\
2001 & Seattle, WA, US & 69 & 218 & 2832 & 3.43 & 1.09 & 41.04 \\
2002 & Minneapolis, MN, US & 61 & 216 & 1726 & 3.74 & 1.06 & 28.30 \\
2003 & Fort Lauderdale, FL, US & 75 & 244 & 1435 & 3.55 & 1.09 & 19.13 \\
2004 & Vienna, AT & 93 & 296 & 1815 & 3.33 & 1.05 & 19.52 \\
2005 & Portland, OR, US & 93 & 285 & 1947 & 3.28 & 1.07 & 20.94 \\
2006 & Montreal, QC, CA & 151 & 477 & 2250 & 3.54 & 1.12 & 14.90 \\
2007 & San Jose, CA, US & 182 & 523 & 2620 & 3.43 & 1.19 & 14.40 \\
2008 & Florence, IT & 218 & 697 & 2361 & 3.64 & 1.14 & 10.83 \\
2009 & Boston, MA, US & 277 & 814 & 2358 & 3.48 & 1.19 & 8.51 \\
2010 & Atlanta, GA, US & 302 & 937 & 2384 & 3.64 & 1.17 & 7.89 \\
2011 & Vancouver, BC, CA & 409 & 1286 & 2861 & 3.71 & 1.18 & 7.00 \\
2012 & Austin, TX, US & 369 & 1128 & 2616 & 3.71 & 1.21 & 7.09 \\
2013 & Paris, FR & 391 & 1285 & 3443 & 3.89 & 1.18 & 8.81 \\
2014 & Toronto, ON, CA & 465 & 1487 & 3001 & 3.87 & 1.21 & 6.45 \\
2015 & Seoul, KR & 484 & 1628 & 2896 & 4.08 & 1.21 & 5.98 \\
2016 & San Jose, CA, US & 545 & 1841 & 3624 & 4.10 & 1.21 & 6.65 \\
2017 & Denver, CO, USA & 600 & 2043 & 2939 & 4.22 & 1.24 & 4.90 \\
2018 & Montreal, QC, CA & 665 & 2336 & 3182 & 4.39 & 1.25 & 4.78 \\
2019 & Glasgow, SCT, GB & 702 & 2561 & 3800 & 4.42 & 1.21 & 5.41 \\
2020 & Honolulu, HI, US & 760 & 2617 & 3474 & 4.29 & 1.26 & 4.57 \\
2021 & Yokohama, JP & 713 & 2453 & 3553 & 4.34 & 1.27 & 4.98 \\
\hline
\end{tabular}

Similarly, the conference has seen an increase in the number of authors contributing to each paper, from an average of 3.29 in 2000 to a high of 4.42 by 2019 .

Historically, conferences have provided an important opportunity for the research community to come together and exchange ideas. However, the significance of this aspect of conferences is starting to be called into question [20]. At the turn of the millennium $\mathrm{CHI}$ attracted around 40 attendees per published paper, disseminating our work. By 2018 that had dropped to 4.78. Combined with an increasingly author heavy attendance [16], despite expansion, the conference may actually be becoming more insular.

Total Travel Impact

To estimate the overall $\mathrm{CO}_{2}$ emissions from attendee travel, a three stage approach was used. First, the developed attendance model was provided with both the collected author makeup, or where unknown the typical makeup for the 20-year period, and the distance between each origin and the conference location. The resulting make up was applied to the known, or projected, attendance. As an example of this step, Figure 1 shows these estimates for the US origin attendees. Additionally, it allows for comparison of these estimates with the reported survey data for the 2008-15 period, where $27-61 \%$ of attendance was of US origin.

Second, using the lower of the ICCT air travel figures or EPA vehicle emissions (or zero for distances below $80 \mathrm{~km}$ ), the nominal $\mathrm{CO}_{2}$ emission figure is calculated for one-way travel between the conference location and the nominal location of the attendees, as described earlier. Finally, the attendance figures are multiplied by the nominal $\mathrm{CO}_{2}$ emissions figures, providing an overall one-way estimate.

As seen in Figure 1, as attendance has grown so have emissions. The lowest estimated travel emissions for the 


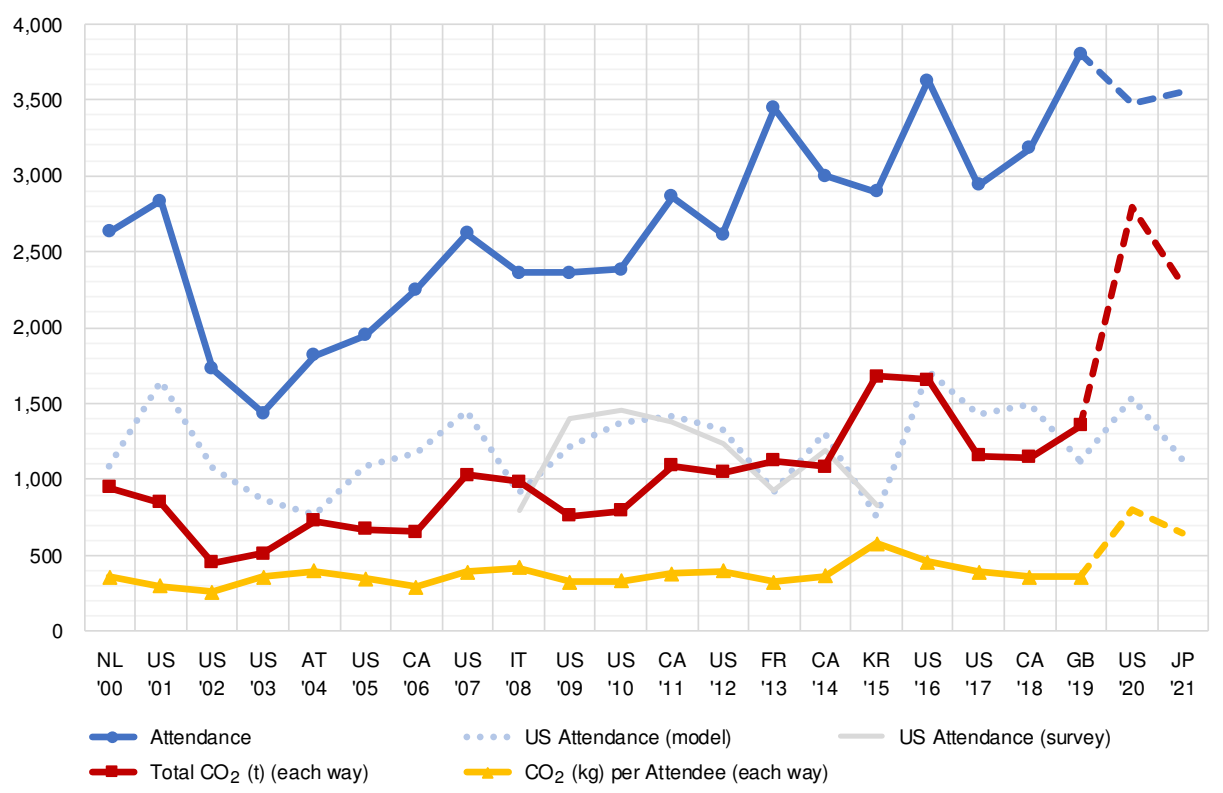

Figure 1: Conference attendance; estimated US attendance, based on the attendance model; estimated actual US attendance, based on survey responses; total estimated travel emissions in metric tons, each way; and estimated travel emissions in kg per attendee, each way.

twenty-year period occurred for the 2002 and 2003 conferences, at 451 and 512 metric tons, one-way, respectively. This coincided with the lowest attendance in the dataset, 1,726 in 2002 and 1,435 in 2003. Interestingly, this remarkably low attendance is coincident with record low acceptance rates for papers submitted to the main proceedings: $15 \%$ and $16 \%$. While it may be unpopular with authors, and seemingly attendees, exceptionally restrictive acceptance criteria may represent a mechanism to lower emissions.

Attendance is not the only possible causal factor driving emissions detectable in the data. Despite higher atten- dance in every year since, $\mathrm{CHI} 2015$, held in Seoul, South Korea, retains the dubious honour of the record for highest total estimated travel emissions: 1,678 metric tons, one way for just 2,896 attendees. A round-trip estimate for travel emissions of 3,355 metric tons $(0.003 \mathrm{Mt}$ ) for this single 6-day conference is greater than the entire annual $\mathrm{CO}_{2}$ emissions of the Faroe Islands (0.002 Mt [13]), the Danish archipelago with a population of over 49,000 people.

The reason for such high estimates is that emissions are a function of distance. As the cumulative distance between individual attendees and the conference location increases, so do the attributable travel emissions. As indicated by the per attendee $\mathrm{CO}_{2}$ emissions, in Figure 1, and found in the underlying distance calculations, Seoul required the longest average per attendee travel in the conference's history.

There are, of course, rational reasons for arranging conferences in locations inconvenient for the typical attendee profile. Attempts to increase the diversity of the author and attendee make up is one such rationale. It was expected that hosting $\mathrm{CHI}$ in Asia would positively influence contributions from that region of the globe [15].

The dataset shows that in $2015,1.69 \%$ of authors indicated an institutional affiliation in Korea, more than double the 2014 figure of $0.83 \%$. Further, based on SIGCHI's published survey data, $11.65 \%$ of attendees indicated their main working location being in Korea, and $25.4 \%$ of attendees reported an origin within a $4,000 \mathrm{~km}^{9}$ radius of the conference, far higher than the $7.28 \%$ combined average from those counties for the 2008-15 period covered by the surveys. By this measure, $\mathrm{CHI} 2015$ was a great success.

Depending on the conference location, overall per-attendee

${ }^{9}$ Approximate distance after which a flight is considered "long haul." 
emissions, each way, vary from a low of $261 \mathrm{~kg}$ to 579 $\mathrm{kg}$, with an overall mean of $374 \mathrm{~kg}$. Authors, as a subpopulation, have slightly different emissions characteristics with each-way figures ranging from $238 \mathrm{~kg}$ to $731 \mathrm{~kg}$, though they are generally slightly higher with a mean of $453 \mathrm{~kg}$. These figures are in line with the work of Spinellis and Louridas [17], who, from a sample of authors and conferences between 1997 and 2009, estimated the overall global round trip average to be $801 \mathrm{~kg}$ ( $\approx 400 \mathrm{~kg}$ each way).

While location clearly impacts attendee make up, due to the persistent attendance of US- and European-based attendees, emissions for such distant locations will be higher. To reduce $\mathrm{CO}_{2}$ emissions, without limiting attendance, therefore requires minimising the distance travelled for these perennial attendees. A weighted average of the origin locations for the full twenty years suggest that the attendee centre of population is in the region of $41.8,-36.0$. A location in the middle of the North Atlantic, and approximately 990 km North West of Ponta Delgada, Azores.

Despite the almost convenient location of the Azores, a part of Portugal and subject to the EU Schengen Agreement (allowing visa free travel for around 400 million people), the small size of the archipelago makes it unsuitable as a conference venue. To support conference attendance, even the largest city would add more than $5 \%$ to its normally resident population. In addition, the small size and remote location means that any conference would have limited scope to attract local or regional attendees, therefore ensuring that essentially all attendees must travel large distances. A problem common to mid-oceanic island locations.

\section{Discussion}

Environmental impact is an acknowledged concern of the community. The ACM have recently begun to make moves to reduce the carbon footprint of their conferences, offering an opt-in carbon offsetting program ${ }^{10}$. Further, $\mathrm{CHI}$ organisers have made explicit their interest in improving the sustainability of the conference, creating a sustainability role, for the first time, for the 2019 conference [6].

\section{CHI 2020: Honolulu, HI, USA}

The $\mathrm{CHI} 2020$ conference is being held in Honolulu, HI, USA at the Hawaii Convention Center. Of the 58 awards the centre lists ${ }^{11}, 9$ are for "green" initiatives of which 3 were grants to pay for renovations. Hawaii is approximately 4,000 km from the nearest land-mass: the continental United States. As a US state Hawaii affords "domestic" travel status for an American audience, and is a popular travel destination. The attendance model, as seen in Figure 1, predicts an increased US attendance compared with 2019.

Future attendance estimates are forecast using a simple linear regression and, for 2020, this predicts a slight drop in overall attendance. Despite this, as shown in Figure 1, travel related $\mathrm{CO}_{2}$ emissions are forecast to be the highest ever. At an estimated 2,791 metric tons, each way, this is a $66 \%$ increase on the current record holder, 2015. This should not be surprising. Hawaii has long been noted as a particularly high carbon intensity destination [17]. While this estimate is a forecast, due to the island's remote location, to avoid becoming the most carbon intensive conference in CHI's history it would need to see non-local attendance drop to fewer than 2,000, a level not seen since 2005.

CHI 2021: Yokohama, Japan

Due to the advanced forward planning required for a conference of its size [6], the location for $\mathrm{CHI} 2021$ has already

\footnotetext{
10 https://www.acm.org/special-interest-groups/volunteer-

resources/conference-planning/conference-registration\#carbon

$11 \mathrm{https}: / /$ www.meethawaii.com/convention-center/about/hawaiiconvention-center-awards-accolades/
} 


\section{Carbon Offsets}

Very simply, the UN Clean Development Mechanism

(CDM), defined in the Kyoto Protocol, creates a global market for carbon emissions. Credits are generated for not emitting $\mathrm{CO}_{2}$ in hypothetical future activities. As this future activity is coupled to an economic incentive, this mechanism may be abused by those claiming for reductions on emissions that would never have actually occurred [2, 21]. Additionally, credits may be accumulated for activities undertaken to sequester carbon from the atmosphere. The most popular of which, tree planting, stretches the definition of "long-term" sequestration, particularly for trees which may later be felled or burned [5]. Further, subsequent negative emissions have been found to be less impactful than the initial positive emissions, making effective offsetting even more of a challenge [22]

Even when effective, carbon offsets present an ethical quandary: is emitting and offsetting morally acceptable if it is morally worse than not emitting at all? [8] been determined. In 2021, CHI will make a return to Asia and, for the first time, it will be located in Yokohama, Japan. Local attendance is forecast to be $11.5 \%$, much higher than the more typical value of around $2 \%$ for attendees that travel from Japan. This boost in local attendance is similar to that of other recent conference locations outside of North America e.g. Paris, France (2013), 8.6\%; Seoul, Korea (2015), 11.7\%; and Glasgow, UK (2019), 13.9\%.

Despite the high levels forecast for local attendance, like Hawaii and Korea, Japan actually represents a substantia travel commitment for the typical $\mathrm{CHI}$ attendee. The forecast, shown in Figure 1, estimates a total of 2,285 metric tons of $\mathrm{CO}_{2}$ emitted by travel, each way. This forecast assumes a continued upwards trend in total attendees. However, even if attendance dropped to 2,896, the 2015 level when the conference was last held in Asia, the model predicts emissions $11 \%$ higher than for the Korean conference. To drop below Korea for total carbon intensity from travel, attendance would need to fall below 2,500. From an exclusively carbon focused point of view, Japan represents the second worst planned location for $\mathrm{CHI}$ since its inception.

\section{Low Carbon Alternatives}

If the ACM, and the community, are serious about sustainability and reducing how carbon intensive our premier conference has become, we must face some uncomfortable practical limitations. In closed systems, sustainable growth is an oxymoron [3]. Aircraft are, essentially, as efficient as they are likely to become [11]. While attractive, carbon offsets (see sidebar) are of debatable effectiveness [2, 5, 21] and raise troublesome ethical questions [8].

To effectively reduce emissions, failing an enormous and unexpected improvement in the emissions characteristics of intercontinental transport, we must minimise the movement of people. We can most easily do this through two mechanisms: reduce attendance, or reduce the distance attendees travel. While these mechanisms are not mutually exclusive, it is acknowledged that the former is unlikely to be popular with authors, attendees, the committee, or conference sponsors. Therefore, in the short term, we must settle for minimising attendee travel, and we can achieve this by optimising the location of these conferences.

As with 2021, the planning for 2022 and 2023 is already underway $^{12}$. CHI 2021 is to be located in North America, and 2022 in Europe. As noted in the results, the estimated centre of population for $\mathrm{CHI}$ attendees is located in the midNorth Atlantic. Choosing locations on either side of this divide will, likely, reduce the total travel of $\mathrm{CHI}$ attendees without negatively affecting attendance. In fact over the last decade the lowest travel emissions, on a per-attendee basis, have been Paris, France (2013), Atlanta, USA (2010), and Glasgow, UK $(2019)^{13}$. Each of these conferences demonstrated growth in year-on-year attendance. With this in mind, this paper calls on the committee to preferentially consider locations on the East-coast of North America for 2022 and in Western Europe for 2023

Going forward, more radical solutions may be required. While the aforementioned conference locations produced the lowest per-attendee travel emissions of the previous ten years, along with attendance, each represented yearon-year growth in total $\mathrm{CO}_{2}$ attributed to travel. Carefully selecting venues can only be one part of the solution to the challenge of reducing the carbon intensity of $\mathrm{CHI}$.

Experimental remote presence technologies, such as Beam, have been trialed at some previous $\mathrm{CHI}$ conferences including $\mathrm{CHI} 2017$ and 2018. Remote presence devices

12 https://chi.acm.org/chi-series/

${ }^{13}$ Closely followed by Montreal (2018) and Toronto (2014), Canada 
are challenging to implement and physically limited, both in scope and number [14]. These limitations precluded their use at $\mathrm{CHI} 2019$, and, due to their physical nature, they still require massive infrastructure and continue to consolidate the idea and ideal of large, centralised conference venues.

Expansion of video-based experiences, such as streaming and on-demand access, is already endorsed by the committe ${ }^{14}$ and offers much more broadly accessible options for remote attendees. Further, supporting low-cost, local events, such as the ACM SIGCHI Asian Development Committee's Best of CHI2019 event at IIT Bombay, India ${ }^{15}$, can replicate much of the conference experience, foster collaboration, and disseminate ideas with much lower overheads.

In the future, the application of augmented- and virtualreality may offer huge opportunities for bringing people together, replicating much of the traditional conference experience without the physical requirements and limitations of the current real-world approach. Such radical proposals may finally fulfil the promises of platforms such as Second Life, once hailed as the future of business and industry [10].

\section{Limitations}

This work presents reasoned estimates for the magnitude of travel emissions directly attributable to $\mathrm{CHI}$ conference travel. Its purpose is to surface discussions and consider the impact of conference location as a potential environmental concern for SIGCHI, the ACM, and the broader conference community. However, the accuracy of the estimates presented in this work suffer from a number of limitations inherent in the data, and lack thereof, discussed here.

\footnotetext{
${ }^{4}$ https://chi.acm.org/policies-processes/chi-live-andrecorded-video-policy/

15 https://www.indiahci.org/best-of-chi2019/
}

\section{Point of Origin}

As stated earlier, for the purposes of this work, it is assumed that authors travelled both to and from the conference from their affiliated institution. While for many travellers this may be a reasonable assertion, there are a multitude of reasons why this may not be true. Mundane reasons may include misidentified institutions, errors in tagging, and authors located away from their affiliated location either permanently or at time of travel.

For frequent travellers, including those "out of place" or already travelling for other reasons, it may be possible for them to combine trips. For these individuals travel to and from the conference may be shorter than calculated, or conversely further. In complex cases, even with accurate travel documentation, the contributing impact of the conference location cannot be precisely determined. Factors such as reducing total journeys, or making additional detours, and the relative weighting of consequential travel plans may impact the total distance and how much of the total journey should be apportioned to a particular event.

\section{$\mathrm{CO}_{2}$ Emissions}

The $\mathrm{CO}_{2}$ emissions presented in this work considers only the two major forms of transportation: personal vehicle, and air. While these make up over $95 \%$ of all journeys, where possible attendees may choose to use alternative travel modes such as buses and trains which typically have lower emissions. Local journeys also represent a gap in the travel survey data used, and these journeys may reasonably be taken by zero-emission modes of transport. Due to this gap and the precise point of origin being unavailable, journeys below $80 \mathrm{~km}$ are zero-rated, as would be typical for bicycle or foot. Conversely, local attendees may equally chose public transport which would typically have higher emissions than the zero-rating applied in these estimates. 
Further, while the ICCT aircraft emissions model provides a comprehensive overview of typical $\mathrm{CO}_{2}$ emissions, these figures may not necessarily be representative of actual attendee emissions. For example, attendees may transport atypical luggage or have a different travel-class make up than the global population. This limitation also applies to typical personal vehicle $\mathrm{CO}_{2}$ emissions. Individual conference attendees may have differing passenger or vehicle characteristics (e.g. electric, hybrid, gasoline, or diesel). As such it is important to consider these estimates in aggregate. While some attendees will be responsible for greater emissions, others may be responsible for fewer.

\section{Total Attendance}

Over the period this work covers, unique authors have increased from 216 (2002) to over 2,500. However, total attendance is $1.5-13 \times$ higher than author attendance. To determine the attendance make up, this work includes consideration of the authors overall travel characteristics, which may or may not be representative of the broader $\mathrm{CHI}$ attendees. However, as indicated by the published survey data, a large and growing proportion of attendees are authors.

Further, the survey data, used in calculating the coefficients for attendance, is not available after 2015, impacting potential accuracy. Finally, while the attendance model builds upon statistically significant regressions and provides robust estimates for the best represented origin countries, estimates for origins less well represented in the survey data may be less reflective of actual attendance. For origins that are poorly represented, discrepancies may suggest additional, or alternative, causal factors which drive attendance.

\section{Conclusion}

This work highlights the scale of emissions attributable, at least in part, to the travel undertaken to attend the $\mathrm{CHI}$ conference. Unfortunately, for those with a view to reduce $\mathrm{CO}_{2}$ emissions, the immediate future looks troubling.

The limitations discussed should not negate the importance of considering the potential environmental impact of conference travel. Whether convinced by the analysis herein, or not, attendees do travel to conferences. The distance travelled is determined by location. And, be they minuscule or mammoth, travel results in emissions.

As a community we are uniquely placed to walk the walk, not just talk the talk. We are $\mathrm{HCI}^{16}$. While remote presence devices have been trialed at some previous conferences, they remain challenging to implement and physically limited [14]. However, augmented- and virtual-reality, technologies familiar to $\mathrm{CHI}$ attendees and prevalent in $\mathrm{CHI}$ papers, may offer alternative approaches in the future.

The purpose of this work is not to guilt-trip or moralise. To be explicit, the message is not "don't travel." Rather, these findings should prompt us to ask ourselves, both as individuals and a community, when, where, and why?

If we are comfortable with the trade-off, convinced the social good outweighs the potential harm, then we might also feel comfortable continuing as we are, pursing our gradual moves towards improving sustainability. If not, together, we should consider whether current growth and practices are sustainable and ethical, and how we can apply our own experience and expertise to the challenges that changing research communications would entail.

\section{Acknowledgements}

This work was supported by EPSRC grant EP/R004471/1. Data available from: https://doi.org/10.17863/CAM.48681

\footnotetext{
${ }^{16}$ This was the theme of $\mathrm{CHI} 2010$.
} 


\section{REFERENCES}

[1] Christoph Bartneck and Jun Hu. 2009. Scientometric Analysis of the $\mathrm{CHI}$ Proceedings. In Proceedings of the SIGCHI Conference on Human Factors in Computing Systems. ACM, 699-708.

[2] Adam G. Bumpus and Diana M. Liverman. 2008. Accumulation by Decarbonization and the Governance of Carbon Offsets. Economic Geography 84, 2 (2008), 127-155.

[3] Herman E. Daly. 1990. Sustainable Growth: An Impossibility Theorem. Development 1990, 3/4 (1990), 45-47.

[4] Steven J. Davis, Nathan S. Lewis, Matthew Shaner, Sonia Aggarwal, Doug Arent, Inês L. Azevedo, Sally M. Benson, Thomas Bradley, Jack Brouwer, Yet-Ming Chiang, Christopher T. M. Clack, Armond Cohen, Stephen Doig, Jae Edmonds, Paul Fennell, Christopher B. Field, Bryan Hannegan, Bri-Mathias Hodge, Martin I. Hoffert, Eric Ingersoll, Paulina Jaramillo, Klaus S. Lackner, Katharine J. Mach, Michael Mastrandrea, Joan Ogden, Per F. Peterson, Daniel L. Sanchez, Daniel Sperling, Joseph Stagner, Jessika E. Trancik, Chi-Jen Yang, and Ken Caldeira. 2018. Net-Zero Emissions Energy Systems. Science 360, 6396 (June 2018). DOI :

http://dx.doi.org/10.1126/science. aas9793

[5] Christian Downie. 2007. Carbon Offsets: Saviour or Cop-Out? Vol. 48. Australia Institute.

[6] Adrian Friday, Oliver Bates, Christian Remy, and Mike Hazas. 2019. Talking about $\mathrm{CHI}$ and Sustainability. https://chi2019.acm.org/2019/02/22/talking-about-chiand-sustainability/. (Feb. 2019)
[7] Brandon Graver, Kevin Zhang, and Dan Rutherford. 2019. CO2 Emissions from Commercial Aviation, 2018. Technical Report 2019-06. ICCT. 13 pages.

[8] Keith Hyams and Tina Fawcett. 2013. The Ethics of Carbon Offsetting. Wiley Interdisciplinary Reviews: Climate Change 4, 2 (2013), 91-98.

[9] IPCC. 2019. Special Report, Global Warming of $1.5^{\circ} \mathrm{C}$ (SR15). Technical Report SR15.

[10] Andreas M. Kaplan and Michael Haenlein. 2009. The Fairyland of Second Life: Virtual Social Worlds and How to Use Them. Business horizons 52, 6 (2009), 563-572.

[11] David MacKay. 2008. Sustainable Energy - without the Hot Air. UIT Cambridge.

[12] N McGuckin and A Fucci. 2008. Summary of Travel Trends: 2017 National Household Travel Survey. Technical Report FHWA-PL-18-019. U.S. Department of Transportation.

[13] M Muntean, D Guizzardi, E Schaaf, M Crippa, E Solazzo, J.G.J Olivier, and E Vignati. 2018. Fossil CO2 Emissions of All World Countries: 2018 Report. OCLC: 1111210409.

[14] Carman Neustaedter and Anthony Tang. 2019. Explorations of Remote Attendance at $\mathrm{CHI}$. https://chi2019.acm.org/2019/02/15/explorations-ofremote-attendance-at-chi/. (Feb. 2019).

[15] Daisuke Sakamoto. 2015. Asian Researchers at the CHI Conference. interactions 22, 1 (Jan. 2015), 52-55. DOI : http://dx.doi.org/10.1145/2692310 
[16] SIGCHI. 2019. Conference History: $\mathrm{CHI}$. https://sigchi.org/conferences/conference-history/chi/. (2019).

[17] Diomidis Spinellis and Panos Louridas. 26-Jun-2013. The Carbon Footprint of Conference Papers. PLOS ONE 8, 6 (26-Jun-2013), e66508. DOI : http://dx.doi.org/10.1371/journal . pone. 0066508

[18] United States Environmental Protection Agency. 2008. Greenhouse Gas Emissions from a Typical Passenger Vehicle. Technical Report EPA-420-F-18-008.

[19] U.S. Department of Transportation. 2019. Table 4: Percent of Trips by Mode for One Way Travel Distance. https://www.bts.gov/archive/publications/america_on_ the_go/long_distance_transportation_patterns/table _ 04. (2019)
[20] Moshe Y. Vardi. 2020. Publish and Perish. Commun. ACM 63, 1 (Jan. 2020), 7. DOI :

http://dx.doi.org/10.1145/3373386

[21] Michael W. Wara and David G. Victor. 2008. A Realistic Policy on International Carbon Offsets.

Program on Energy and Sustainable Development Working Paper 74 (2008), 1-24.

[22] Kirsten Zickfeld, Andrew H. MacDougall, and H. Damon Matthews. 2016. On the Proportionality between Global Temperature Change and Cumulative $\mathrm{CO} 2$ Emissions during Periods of Net Negative $\mathrm{CO} 2$ Emissions. Environmental Research Letters 11, 5 (May 2016), 055006. DOI :

http://dx.doi.org/10.1088/1748-9326/11/5/055006 


\section{Commentary}

For alt.chi paper

CHI 2020: Right Here, Right Now?

\section{Hüseyin Uğur Genc}

Koç University - Arçelik Research

Center for Creative Industries

34450 İstanbul, Turkey

hgenc17@ku.edu.tr
The study scans the history of $\mathrm{CHI}$ and analyzes them in terms of $\mathrm{CO} 2$ emission rates that were produced by attendees, and it makes predictions about the $\mathrm{CHI}$ '20 and ' 21 . And it discusses the ways to mitigate this harm of the conferences in both the short and long terms.

First of all, I want to appreciate the author for his great effort to untap the environmental impact of CHIs. All data were gathered, and the statistical calculations are well-established and enough to reveal the situation. This topic could not be more appropriate, as we are witnessing one of the biggest environmental crises of history, the conflagration of Australia. And, I am really grateful to see this paper at the conference to raise awareness about the issue.

As the author already mentioned, the CHI committee already started to deal with the sustainability problem of conferences. From the selection of the convention centers to the technologies which provide a new kind of a participation experience, new solutions are being and will be tried. From this perspective, the discussion part of the paper should be improved in terms of suggestions. In addition to

"Low Carbon Alternatives", the paper may also include suggestions such as "Reverse Carbon Alternatives". In today's world, even we choose cloud computing instead of printing our papers, because of the data centers, we emit almost the same amount of $\mathrm{CO} 2$ emissions. In events like $\mathrm{CHI}$, the situation is also the same. Howsoever local it may be or howsoever close it may be, the conferences will emit $\mathrm{CO} 2$. But as a counteraction, we can neutralize these emission rates. For example, on our conference registration page, for each author, there might be a list includes unique to-dos, to decrease our impact. As an individual, attendees take a role in this problem. Another suggestion, one of the conference days might be selected for an arbor day. All the participants might plant one or more trees on that day.

In brief, this paper is strong in topic, data, and analysis. But it needs to discuss this environmental issue in other perspectives. As the author mention, "As a community, we are uniquely placed to walk the walk, not just talk the talk. We are HCI.". and we need to show this ability in this problem.

As a member of this community, I, again, want to thank the author to bring this issue into question. 